\title{
Influence of Trust on the Spread of Mobile Terminal Products
}

\author{
Wang Sailan \\ Architecture and Urban Planning College, Southwest Minzu University, Cheng Du, Si Chuan, 610041, China
}

\begin{abstract}
In the era of mobile Internet, expanding the spread influence is an effective way to obtain the competitive advantage for mobile terminal products. Based on the technology acceptance model and expectation confirmation theory and combined with the characteristics of tourism mobile commerce, a theoretical model was constructed to influence the degree of trust in mobile service. The questionnaire survey of 240 users who used the tourism mobile commerce as the data source paid special attention to the establishment of the trust degree, and proved that expectation confirmation, brand recognition and interpersonal communication were the key influence factors on the degree of trust.
\end{abstract}

\section{Introduction}

The China Mobile Phone Helper User Behavior White Book 2014 released by iResearch showed that the number of mobile users in 2013 in China was up to 0.5 billion, the permeability rate was $81 \%$, and the increasing rate of mobile user numbers was nearly $10 \%$ larger than that of overall Internet users. Moreover, along with the improvement of the Internet environment, the monthly use time of mobile users surpassed that of PC users, and the user stickiness of mobile phones was largely increased. ${ }^{1}$ It can be stated that the network user behaviors are transferring to mobile terminals, and the mobile-Internet is increasingly influencing the life of humans and becomes a major place for commercial competition. As reported, the trust factors considerably affect the behaviors of mobile users. However, the generation and influence of trust factors under the mobile environment are both different compared with usability and satisfaction degree. In this study targeting tourism mobile commerce, the effects of trust factors on the transmission in mobile end software were analyzed, and the ways to increase user stickiness by enhancing the trust degree were proposed. This study is of practical and guiding significance for tourism mobile commerce research \& development institutions during their targeted technique development, marketing \& promotion, and for them to increase user stickiness \& retention.

\section{Research advances}

The definitions of "trust" are diverse and differ among the fields of psychology, philosophy, management science, and market selling. The generalized "trust" can be explained by the organization trust integration model from Mayer et al. This theory holds that the keys of trust generation are the capability, straightness and kindness of the trusted party. The result of trust is the willingness of the trust giver to undertake the risks of actions. ${ }^{2}$ Under the virtual environment, the relatively famous definition of "trust" is the trust model from McKnight et al. (2002): trust in the Internet comes from three aspects, including interpersonal relations, systems, and the inclination of individual trust. ${ }^{3}$ Zhou Tao divided the trust problem of E-commerce into four dimensions, including capability, faith, honesty and predictability. ${ }^{4}$ Based on existing knowledge, Li Yongjun defined trust as a measure when subject A is willing to offer subject B specific service (or to execute specific action) according to the environment of subject $\mathrm{A}^{5}$. Based on previous studies, we think the trust at the mobile terminal as a subjective evaluation of users about whether the service expected can be acquired through this mobile terminal after users balance the information known. Users will judge, according to some factors, whether this mobile terminal can be trusted, and the degree of trust is also decided by these factors, which are the focus of research on trust.

In the field of Internet, the influence factors on trust have been widely studied. For instance, Stanford University from USA studied in 2002 the influence factors on the trust in Internet. It was found that users will trust in a certain website because of many factors: favorable experience of browsing, clear ways of contact, fast response to users' questions, ever seeing ads of this website, association between the ads and the contents of the website, completeness of information, information searching function, information of authors, major of web page design, and declaration on user information protection. Other factors include affirmed emails sent, real-time contact, convenience of page printing, frequent updating of page contents, and top ranking on Internet search. ${ }^{6}$ Consumer WebWatch, a non-profit institution from USA, issued investigation reports on Internet trust in 2002 and 2005. The report 2005 showed that the factors deciding the trust to a website included inviolation to personal information security, information 
of the website, legibility, frequent update of website information, and known relegation of rights. ${ }^{7}$

The relationship between trust and E-commerce has also been well studied. One important achievement was the doctoral thesis from Davis in 1986 that mentioned the technology acceptance model (TAM) ${ }^{8}$ This model is extremely important for studying the acceptable behaviors of technical products by users. Especially, the perceived ease of use, perceived usefulness, and satisfaction with techniques have been continually applied to Internet products. So far, many researchers have adopted trust as an expanded factor into the TAM model. Wang Wei et al. adopted trust as an intermediary factor and studied the user acceptance model on online tourism websites. ${ }^{9}$ Tan Chunhui evaluated the effects of trust on corporate websites. ${ }^{10}$ The above studies suggest that trust can positively affect Internet products, or namely, trust can promote the consumption desire of users and urge their willingness to buy.

\section{Influence relationship between trust factors and propagation -- targeted at tourism mobile commerce}

\subsection{Research direction}

The existing studies about trust focus on the first-time or

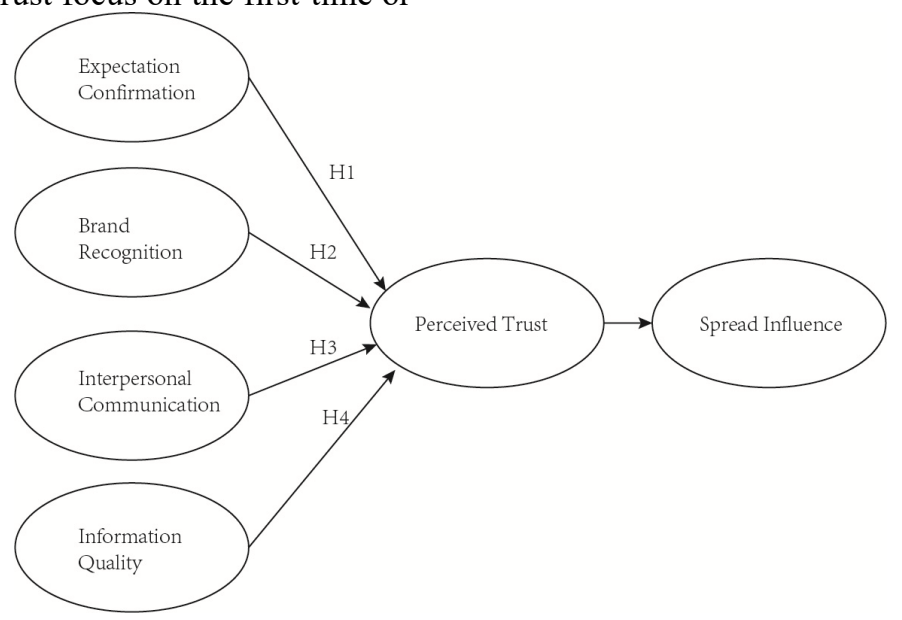

Fig. 1 Structure model

In this model, the four prior factors that decided the degree of trust included expectation confirmation, brand recognition, interpersonal communication, and information quality. Expectation confirmation is a widely-accepted theory in marketing, and customers compare the purchased product or service with the pre-purchase expectation, which is the standard to evaluate their satisfaction. ${ }^{11} \mathrm{We}$ think the expectation confirmation of the trust model is not a one-time process, but is a repeated and multi-time process. In other words, continued successful experience will further solidify the trust of users on a product, indicating there is a positive correlation between two variables. Hence, we propose the first hypothesis that expectation confirmation and perceived trust are positively related:

Null hypothesis $\mathrm{H}_{10}: \rho \leq 0$, there is no positive early-stage purchase. Namely, how to promote the trust of users on a strange product and to induce the first-time consumption? However, there is rare research about the continuous use of trust factors. Most studies focus on confirming the positive effect of trust on continuous use, but have rarely reported how trust can be continued and improved.

In this study based on previous research, we will not validate the confirmed conclusions that trust factors can positively affect the dissemination of mobile commerce. This study is focused on the maintenance and reinforcement of trust relationship between users and mobile service providers during the mobile use. Hence, we adopted the models targeting at the characteristics of tourism mobile commerce, explored the prior variables of trust and analyzed the effects on the spread of mobile end software.

\subsection{Theoretical hypotheses}

Based on the existing research on the conception of trust, ranging from the generalized trust to the trust in E-commerce and together with TAM and expectation confirmation theory (ECT), we proposed a new structural model (Fig. 1). correlation between two variables

Alternative hypothesis $\mathrm{H}_{11}: \rho>0$, there is positive correlation between two variables

where $\rho$ is the rank correlation coefficient between expectation confirmation and perceived trust. At a given significance level $\alpha$, if $p<\alpha$, reject the null hypothesis, namely there is a positive correlation between two variables.

The relationship between brand recognition and use behaviors has been well confirmed. The concept of brand recognition was proposed in the 1970 s, which represented the degree to which consumers were sentimentally attached to a brand. As for mobile commerce, brand recognition can be migrated from the website terminal. For instance, if a user once had booked air ticket or a hotel on Ctrip, he/she was likely to 
download the APP of Ctrip and went on using their services on the mobile end. On the contrary, if the user did not approve the website of this brand, he/she was likely to give up using the mobile end of this brand. Hence, our second hypothesis is that brand recognition and perceived trust are positively related:

$$
H_{20}: \rho \leq 0 \quad H_{21}: \rho>0
$$

where $\rho$ is the rank correlation coefficient between brand recognition and perceived trust.

In the McKnight trust model, interpersonal relation is one of the three sources of trust on Internet. So far, the sharing and exchange of information are increasingly easier, and numerous users will decide whether or not to buy according to the evaluation information on the Internet. On many occasions, user comments and spread can rapidly let customers to decide whether or not to buy. With more positive-comments, the trust on a product is solidified. Our third hypothesis is:

$$
H_{30}: \rho \leq 0 \quad H_{31}: \rho>0
$$

where $\rho$ is the rank correlation coefficient between interpersonal relations and perceived trust.

Information quality decides whether a certain mobile service can provide the information needed by users. It can be stated that information quality is exactly the perceived usefulness. If a product cannot provide users with necessary information, the users may turn to select the products from competitors. As reported, information quality is a key influence factor on the success or failure of E-commerce. Our fourth hypothesis is:

$$
H_{40}: \rho \leq 0 \quad H_{41}: \rho>0
$$

where $\rho$ is the rank correlation coefficient between information quality and perceived trust.

Similarly, hypothesis test on the positive correlation between perceived trust and continued usage intention can be conducted.

\section{Study design}

\subsection{Questionnaire design and recovery}

The variables involved in this study included expectation confirmation, brand recognition, interpersonal communication, and information quality. The four variables were measured by referring to some known scales, with modification according to the characteristics of tourism mobile commerce. A questionnaire was used here. Each variable consisted of 3 items. The questionnaire was designed as a Likert5 scale (1 means "extreme disagreement"; 5 means "extreme agreement"). The subjects investigated were the users of China mobile tourism commerce. All the users had used the tourism products on the Internet. The questionnaire was sent out in two steps. Firstly, in a small-scale preliminary survey, the questionnaire was sent out to several experts in this field and some mobile-Internet senior users. Then the semantic context of this questionnaire was adjusted according to their comments. Secondly, a large-scale online survey was carried out. The survey was conducted on diaochapai.com, the most professional questionnaire survey website in China. To make the survey more universal and targeted, we sent out the questionnaire mainly to Internet communities and instant communication exchange platforms. Moreover, through Internet communication tools, we invited students and graduates from College of Tourism at Sichuan University or Jincheng College of Sichuan University to fill in the questionnaire. An online version of the questionnaire was sent out to workers in Tencent, Jinshan and Sohu.

The recovery rates were very high, as 240 copies were returned within 1 week. Since the subjects should finish all answers before returning, these 240 copies were all valid. The descriptive statistics of samples were listed in Table 1.

Table 1. Descriptive statistics of sample

\begin{tabular}{lll}
\hline Characteristic & Classification & Percent \\
\hline \multirow{4}{*}{ Name of mobile service } & Ctrip & $39.6 \%$ \\
& Qunar.com & $17.5 \%$ \\
& Tuniu.com & $14.6 \%$ \\
& Lvmama.com & $20.8 \%$ \\
& Others & $7.5 \%$ \\
\hline \multirow{2}{*}{ Gender } & Male & $57.5 \%$ \\
& Female & $42.5 \%$ \\
\hline \multirow{4}{*}{ Age } & $<20$ years & $7.1 \%$ \\
& $21-25$ & $35.8 \%$ \\
& $26-30$ & $39.6 \%$ \\
& $31-35$ & $15.8 \%$ \\
& $>35$ & $1.7 \%$ \\
Education level & & \\
& & $15.8 \%$ \\
& High school, technical & school \\
& and below & $23.3 \%$ \\
& Junior college & $45.4 \%$ \\
& Undergraduate & \\
& Postgraduate and above & \\
\hline
\end{tabular}




\begin{tabular}{lll}
\hline & 1 & $31.3 \%$ \\
Times of use & $2-5$ & $44.2 \%$ \\
& $6-10$ & $17.9 \%$ \\
& $11-20$ & $4.6 \%$ \\
& $>20$ & $2.1 \%$
\end{tabular}

The majority (39.6\%) of subjects in this investigation were users of Ctrip, followed by lvmama.com (20.8\%), Qunar.com (17.5\%) and tuniu.com (14.6\%) with insignificant difference, and the remaining $7.5 \%$ of subjects used other tourism mobile service products not listed here. The subjects consisted of $57.5 \%$ of males and $42.5 \%$ of females, and were mostly aged $21-25$ years (35.8\%) and 26-30 years (39.6\%). As for education level, most of the subjects were undergraduates (45.4\%). About $44.2 \%$ of the subjects used the corresponding product 2-5 times.

\subsection{Scale and model testing}

To validate the reliability and validity of the scale, we first tested its confidence and validity. Confidence was tested by using Cronbach $\alpha$ (Alpha) and a Cronbach $\alpha$ (Alpha) $>0.7$ meant the confidence was high. The validity was measured by using KMO test and Bartlett test from factor analysis.

Table 2. Scale test reliability (Alpha)

\begin{tabular}{|c|c|}
\hline Observed variable & $\alpha$ \\
\hline Expectation confirmation & .671 \\
\hline Brand recognition & .822 \\
\hline Interpersonal communication & .801 \\
\hline Information quality & .837 \\
\hline
\end{tabular}

\begin{tabular}{lcc}
\hline \multicolumn{3}{c}{ KMO test and Bartlett test } \\
\hline Kaiser-Meyer-Olkin test with enough degree & .674 \\
& Approximate Chi-square & 1187.63 \\
\multirow{2}{*}{ Bartlett sphericity test } & $\mathrm{df}$ & 6 \\
& $\mathrm{Sig}$. & 465 \\
& & .002 \\
\hline
\end{tabular}

The KMO of the questionnaire was 0.674 , and the significance of Barlett sphericity test was $<0.05$, indicating this questionnaire was reliable.

The accuracy of model 1 was analyzed and validated

Table 3 Adaptation indices of the model

\begin{tabular}{|c|c|c|c|c|c|c|}
\hline Index & $\chi^{2} / \mathrm{df}$ & $p$ & NFI & IFI & RMSEA & CFI \\
\hline $\begin{array}{c}\text { Data } \\
\text { Evaluatio } \\
\text { n criterion }\end{array}$ & $\begin{array}{c}.32 \\
\text { The smaller } \\
\text { the better. }\end{array}$ & $\begin{array}{c}.96 \\
\text { Co.05 }\end{array}$ & $\begin{array}{c}.91 \\
\text { Close to 1 }\end{array}$ & $\begin{array}{c}.869 \\
\text { Close to 1 }\end{array}$ & $\begin{array}{c}.084 \\
\text { Close to 0 }\end{array}$ & $\begin{array}{c}.876 \\
\text { Close to } 1\end{array}$ \\
\hline
\end{tabular}

\subsection{Test of hypotheses}

The results of between-variable correlation hypothesis tests were listed in Table 4. The estimated values and $p$ values of between-variable correlation analysis showed that the hypotheses of positive between-variable correlations were all supported. In other words, the user expectation of getting affirmed trust was stronger; the brand identification of users improved the degree of trust; when the positive suggestions obtained by users from interpersonal communication were more, the trust was severer. However, the positive correlation between information quality and trust degree was slightly weaker. 
Table 4. Correlation estimated values and correlation tests of model variables

\begin{tabular}{c|c|c}
\hline & Perceived trust & p value \\
\hline $\begin{array}{c}\text { Expectation } \\
\text { confirmation }\end{array}$ & $.620^{*}$ & .031 \\
\hline Brand recognition & $.747^{* *}$ & .006 \\
\hline $\begin{array}{c}\text { Interpersonal } \\
\text { communication }\end{array}$ & $.802^{* *}$ & .004 \\
\hline Information quality & $.514^{*}$ & .043 \\
\hline $\begin{array}{c}\text { Continued usage } \\
\text { intention }\end{array}$ & $.918^{* * *}$ & .000 \\
\hline
\end{tabular}

Note: ${ }^{*} \mathrm{p}<0.05 ; * * \mathrm{p}<0.01 ; * * * \mathrm{p}<0.001$.

Figure 2 showed the path coefficients and

significance of the model.

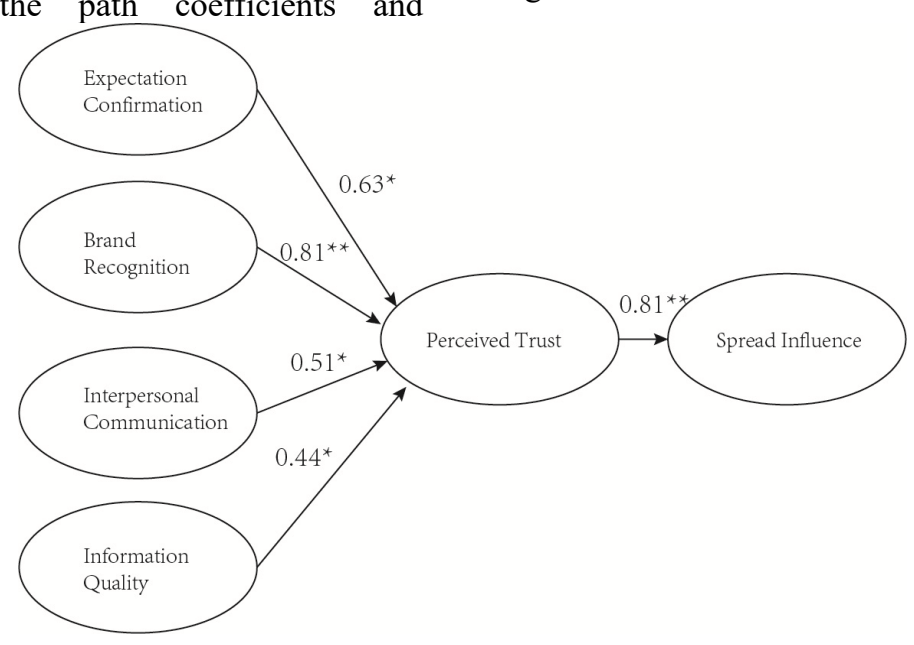

Fig. 2 Structure model

\section{Conclusions and analysis}

Along with the rapid development of mobile phones, mobile-Internet has been changing the living, consuming and entertaining ways of humans at considerable rates. The mobile commerce is upsurging and shows a prospective future. Research on mobile commerce has never stopped, ranging from commercial success and huge market to the popular discussion in academia. Based on TAM and ECT and together with the consumer retention theory from marketing and management science, we built and validated a model concerning the influence on the spread of tourism mobile commerce products. This study has two contributions from theoretical and practical perspectives.

Theoretically, this study modestly enriches the theoretical research on tourism E-commerce. The research target of this study is tourism mobile commerce, which has not received much attention from previous similar research. We used an information system user continued use behavior model, which has been applied extensively in the fields of marketing and management. The usability of the mobile terminal was evaluated using a quantitative method, bringing a new method for quantitative research in the future.

Practically, the spread influence is the key factor deciding the success or failure of a mobile product. The findings in this study can guide the management practice of tourism mobile commerce and are practically meaningful for research \& development institutions. Based on the four influence factors mentioned in this study, enterprises in this field can improve products from the perspectives of research \& development, management, and maintenance and can thereby increase market shares and profits.

(1) Repeated and multiple successful experiences can positively solidify user trust. The investigation results showed that most users, after the first-time use of booking tourism products on mobile terminals, were more likely to choose lower-price products and will gradually increase the amount of costs after successful experience. It was indicated the trust of users on this service was gradually enhanced. Hence, service providers should appropriately provide low-cost products, since users will have trust after multiple confirmations of reliability.

(2) The brand recognition by users was very important for the establishment of first-time trust and persistent trust. Most users will choose popular mobile service providers, such as Ctrip and lvmama.com. The Internet terminal brands also influenced the mobile terminal brands, as mentioned above. Users were also interested in the brands without exclusive tourism mobile commerce services. Up to $34 \%$ of subjects were willing to trust and consider the tourism mobile end executive services offered by Tencent, Netease and other 
famous Internet brands.

(3) Users were likely to trust the information from interpersonal spread. Users trusted more on spread among highly-associated friends (or relatives), but were also interested in the comments from weakly-associated users (strange Internet friends). Furthermore, as for opinion leaders of tourism, the users replied very indifferently and mostly were not interested in their comments and thereby cannot trust on them.

(4) As reported, information quality was positively associated with the spread force, but our study rejected the hypothesis concerning a positive relationship between information quality and trust degree. Analysis of investigation data showed that users did not relate the sufficiency or timeliness of information to trust, and only accuracy largely affected user trust. Nevertheless, information quality was not a meaningful prior variable of trust.

This study also has some limitations, such as the small sample size. Moreover, the user groups of tourism mobile commerce were scattered, which complicated the data collection. More than half of the respondents to this questionnaire were from universities and famous Internet enterprises, but less data were collected from general Internet communities, which led to a certain bias in the findings. In the future, we expect to collect data more extensively and consider more prior influence factors, which will contribute to the development of tourism mobile commerce.

\section{References}

1. iResearch $[\mathrm{EB} / \mathrm{OL}]$. http://report.iresearch.cn/2298.html

(2014-12-26).

2. Mayer,R.C.,Davis, J.H. \& Schoorman, F.D.An Integrative Model of Organizational Trust [J]. Academy of management Review,1995, 20(3): 709-734

3. McKnight, H.D., Choudhury, V.\& Kacmar,C. The Impact of Initial Consumer Trust on Intentions to Transact with A Web Site: A Trust Building
Model[J]. Journal of Strategic Information System, 2002, 11: 297-323

4. Zhou Tao, Lu Yaobin. Influential factors on initial trust of Internet users based on ELM[J]. China Journal of Information systems, 2009(3): 48-56.

5. Li Yongjun, Dai Yafei. Research on Trust Mechanism for Peer-to-Peer Network [J]. Chinese Journal of Computers, 2010, 33(3): 1-18.

6. B.J. Fogg. What makes web sites credible?New study by Stanford University and Makovsky \& Company offers some answers [EB/OL]. www.prnewswire.co.uk/cgi/news/release? id=87005, 2008-07-20.

7. Consumer Reports WebWatch. LEAP OF FAITH: USING THE INTERNET DESPITE THE DANGERS [EB/OL]. www.consumerwebwatch.org/pdfs/princeton.pdf, 2008-07-14.

8. Davis F D. A technology acceptance model of empirically testing new end-user information systems: theory and results[D]. Massachusetts: Sloan School of Management, Massachusetts Institute of Technology, 1986:78-80.

9. Wang Wei, Liu Yu. Empirical study on continued use of emerging online travel sites by consumers -mediating roles of customer satisfaction and trust $[\mathrm{J}]$. Journal of Jinan University (Philosophy \& Social Science Edition), 2014, 36(4): 84-164.

10. Tan Chunhui, Zhao Dan. Research on Fuzzy Comprehensive Evaluating the Degree of Enterprise's Website Trustiness[J]. Information Science, 2009, 27(7): 1094-1099

11. Kim D J, Ferrin D L, Rao H R. A Study of the Effect of Consumer Trust on Consumer Expectations and Satisfaction: The Korean Experience[C]//ICEC '03 Proceedings of the 5th International Conference on Electronic Commerce Pittsburgh. ACM, 2003. 310 -315 . 